\title{
Extending riverbed filtration design velocity for horizontal wells from model to prototypes
}

\author{
S-H. Kim ${ }^{1}$, K-H. Ahn ${ }^{2}$, S.O. Prasher ${ }^{3 *}$ and R.M. Patel ${ }^{3}$ \\ ${ }^{1}$ Department of Environmental Engineering, Yeungnam University, Gyeongsan, South Korea 712-749 \\ ${ }^{2}$ Director, Water Environment and Remediation Center, Korea Institute of Science \& Technology, Hawolgok-dong, \\ Seongbuk-gu, Seoul, South Korea 136-791 \\ ${ }^{3}$ Department of Bioresource Engineering, McGill University, Ste-Anne-de-Bellevue, Quebec, Canada H9X $3 V 9$ \\ Email: shiv.prasher@mcgill.ca
}

Kim, S-H., K-H. Ahn, S.O. Prasher and R.M. Patel. 2012. Extending riverbed filtration design velocity for horizontal wells from model to prototypes. Canadian Biosystems Engineering/Le génie des biosystèmes au Canada 54:1.1-1.6. The design velocity of axial flow through a horizontal well pipe, which was suggested to be about $1 \mathrm{~m} \mathrm{~s}^{-1}$ in a recent model study, was evaluated for its feasibility on prototypes. In order to calculate the head loss during the flow through a horizontal well pipe, the Darcy-Weisbach formula was analyzed using Euler-Cauchy method. When the frictional resistance to the flow in the model well was compared with the one to the flow in prototypes, the latter was found to be smaller than the former. However, the design axial velocity obtained from the model study was also applicable to prototypes. Although uniform discharge intensity is assumed over the entire length of the well and model experimental data is required to calculate head loss in prototype wells, the results of this study may prove useful in predicting well production rate and in determining the required design diameter of horizontal wells. However, further verification with actual prototype is needed. Keywords: Riverbed filtration, horizontal well, axial flow, model, prototype

Récemment, une de nos récentes études portant sur la modélisation suggéra une vitesse nominale d'écoulement axiale à travers une canalisation de puits horizontale d'environ $1 \mathrm{~m} \mathrm{~s}^{-1}$. Dans la présente étude, il fut évalué si cette valeur était raisonnable dans une situation de prototype. Afin de calculer la perte de charge durant l'écoulement à travers une canalisation de puits horizontale, la formule de Darcy-Weisbach fut analysée par la méthode d'Euler-Cauchy. Lorsque la résistance frictionnelle à l'écoulement dans le puits modélisé fut comparée à celle des prototypes, cette dernière s'avéra moindre que la précédente. Cependant, la vitesse nominale d'écoulement axiale obtenue par modélisation s'avéra également applicable aux prototypes. Lors de l'étude, l'intensité de décharge fut considérée uniforme sur toute la longueur du puits et les résultats du modèle expérimental furent nécessaires au calcul de la perte de charge dans les puits prototypes. Les résultats de cette étude peuvent s'avérer utile lors de la prédiction du taux de production des puits horizontaux ainsi que lors de la détermination de leurs diamètres nominaux. Cependant des vérifications additionnelles à l'aide d'un prototype réel sont de rigueur. Mots clés: Filtration fluviale, puits horizontale, écoulement axial, modèle, prototype

\section{INTRODUCTION}

During the last 80 years, horizontal collector wells have been developed for the extraction of groundwater and also for riverbank/bed filtration systems. Horizontal wells have several advantages over vertical wells in areas with limited aquifer thickness and of clogging concerns in having geologic formations fine particles (Hunt et al. 2002a). Owing mainly to their large production capacity, horizontal collector wells for riverbank/bed filtration system have become increasingly popular, especially in the United States (Hunt et al. 2002b), and also in South Korea (Kim 2007). In the United States such can be found in Louisville, Kentucky (Wang 2002) and in Sonoma County, California (Jasperse 2009). In South Korea, about 10 horizontal collector wells have recently been constructed and put into operation, while a further 20 are under construction. Despite their increasing popularity in riverbed filtration systems, the hydraulics of the horizontal collector wells still needs clarification, and design criteria for the full-scale construction are not yet clear (Kim et al. 2008).

The design of lateral pipes in horizontal collector wells is important in determining the pumping rate and filtrate quality during riverbank/bed filtration. An analytical formula for the flow rate of water through a horizontal well lying directly beneath a riverbed was first presented by Hantush and Papadopulos (1962). Zhan and Park (2003) derived an analytical solution for groundwater flowing from a leaky aquifer under a water reservoir into a horizontal well, treating the horizontal well as a line sink and assuming an uniform discharge intensity (flux) along the well. The importance of in-well hydraulics was first recognized by Tarshish (1992). He incorporated in-well flow into a flow simulation for an aquifer beneath a water reservoir and concluded that the discharge intensity was not uniform along the well due to both partial penetration of the aquifer and hydraulic head changes along the lateral pipe. Chen et al. (2003) analyzed in-well flow and the 
aquifer hydraulics simultaneously using numerical techniques. Using a sandbox flow simulator they further concluded that the use of a uniform distribution of discharge intensity along the horizontal well was clearly inadequate. However, since they used a single lateral pipe of fixed diameter and length, their conclusions could not be generalized (Kim et al. 2008). Mohamed and Rushton (2006) incorporated the flow in a shallow unconfined aquifer before entering a horizontal well, the flow from the aquifer into the horizontal well, and the flow within the horizontal well pipe in their model. Comparing model results with the measured data obtained from a practicalscale well, they concluded that the lengthening of a well reduced its efficiency and that uniform discharge intensity over the entire well might be assumed for wells of limited length. However, they did not suggest any criteria for selection of either length or diameter.

Despite the published works on flow analysis to horizontal wells and the long history of the use of collector wells in riverbank/bed filtration, there are a few design criteria reported for horizontal wells. In Europe the design and construction of riverbank/bed filtration systems are based mainly on the engineer's personal experience (Grischek et al. 2002). In the United States, Hantush's formula has been widely used in the riverbank/bed filtration industry (Stowe 2004). Recently, numerical methods assuming constant head on the lateral are also used in the design of the horizontal or collector wells for riverbank/bed filtration (Schafer 2004). However, compared with Darcy's law, Hantush's formula underestimates the production rate of the collector well in riverbed filtration and the numerical methods are questionable when dealing with long horizontal wells, especially with regard to head values assigned to the well under thin aquifer conditions (80-m laterals in aquifers of $10 \mathrm{~m} \sim 20 \mathrm{~m}$ thickness are not unusual in South Korea).

A better design of collector wells for riverbed filtration would be desirable, especially in South Korea, where a high production rate is required in spite of the low aquifer permeability. To address this, Kim et al. (2008) performed a laboratory-scale experiment simulating the lateral pipe of a collector well used for riverbed filtration and analyzed the results using mathematical modeling. According to their study, the distributions of the hydraulic head and discharge intensity along a lateral pipe depend on the balance between two major resistances which the water experiences during the flow towards the collector caisson: (i) resistance to the flow through the aquifer and (ii) resistance to the flow through the lateral pipe. In other words, the head distributions become flattened and the discharge intensity may be assumed to be uniform when the aquifer resistance exceeds the resistance to the flow in the lateral pipes. In this case, the collector well is highly efficient since the drawdown of the water level at the caisson is mostly transmitted up to the other end of the lateral pipe. Kim et al. (2008) reported that main limiting parameter to a well's efficiency was the exit velocity of the axial flow in the horizontal well pipe where it joins the caisson. They suggested velocity of $1 \mathrm{~m} \mathrm{~s}^{-1}$ to be the limit for high efficiency of the collector wells.

There are some questions whether the criteria based on the results of the model experiments, which employed short horizontal wells with small diameters, can be applied to the prototype laterals to achieve high-efficiency horizontal wells. In this study, the applicability to the prototype lateral of the flow criterion derived by Kim et al. (2008) from high-efficiency model horizontal wells, was analyzed using the Darcy-Weisbach formula associated with the Manning's equation for average flow velocity. In the analysis the Euler-Cauchy method was applied to compare head losses in the laterals, and also a comparison of frictions of both model and prototype laterals was made.

Summary of experiment performed by Kim et al. (2008)

Four rectangular acrylic tanks were used, of which three had the same dimensions of width, length, and height $(0.2$ $\mathrm{m}, 0.6 \mathrm{~m}$, and $0.5 \mathrm{~m}$, respectively). The other had a length of $0.8 \mathrm{~m}$ and the same width and height as above. Three different inner diameters $(10 \mathrm{~mm}, 20 \mathrm{~mm}$, and $30 \mathrm{~mm})$ were employed for the model horizontal well pipes. The tanks were filled with filter sand up to $0.46 \mathrm{~m}$ from the bottom. Kim et al. (2008) highlighted the importance of hydraulic conductivity in horizontal wells, thus two different filter sands were used with saturated hydraulic conductivities of $1.55 \mathrm{~mm} \mathrm{~s}^{-1}$ and $0.44 \mathrm{~mm} \mathrm{~s}^{-1}$. A model collector caisson was installed at the end of the connected sand tanks. The caisson had 3 outlet holes, all of which were $50 \mathrm{~mm}$ in diameter and the heights of the centers of the holes were $0.15 \mathrm{~m}, 0.25 \mathrm{~m}$, and $0.35 \mathrm{~m}$ from the bottom. Tap water was supplied to the top of the tanks to keep the water depth $30 \mathrm{~mm}$ above the sand surface. In this experiment, the production rates of the horizontal well, the hydraulic heads along the horizontal well pipe, and the discharges at each sand tank were measured. Varying factors included the water level at the collector caisson, the length and diameter of the horizontal well pipe, and the hydraulic conductivity of the filter sand. The results of this study have been analyzed in order to develop design criteria for full-scale prototype.

\section{THEORETICAL DEVELOPMENT}

Kim et al. (2008) showed that the axial flow velocity in a horizontal well pipe varied according to the pumping rate (or the water level at the caisson), the aquifer permeability, and the length and diameter of the well pipe. Also, the drawdown at the caisson was not effectively transmitted to the entire well due to the resistance to axial flow in the horizontal well pipe, especially when the flow velocity was high. They further showed that a sharp drop in well efficiency was observed for high well-to-caisson exit velocities. In this case, the hydraulic head rose and the discharge intensity decreased with increasing distance from the exit of the horizontal well.

A coordinate system was devised to investigate the hydraulic head distribution along the horizontal well 
(Fig. 1). The hydraulic head on the outer surface of the horizontal well pipe, $h(x)$, is decomposed into two parts: (a) the velocity and (b) the pressure heads in the lateral once the filtrate enters the lateral (The elevation heads are assumed to be identical both in the outer surface and in the lateral). This assumes the head loss during the passage through the screen wall to be negligible (Kim et al. 2008). If the exit velocity of the horizontal well is designated as $v(0)$, the Darcy-Weisbach formula can be used to obtain the head distribution, $h(x)$. The head difference between two points, $\Delta h$, a short distance $(\Delta x)$ apart from each other along the well, can be determined by the equation

$$
\Delta h=f \frac{\Delta x}{D} \frac{v^{2}}{2 g}
$$

where $f$ is the friction factor (unitless), $D$ is the well diameter $(\mathrm{m}), v$ is the axial flow velocity in the well pipe $\left(\mathrm{ms}^{-1}\right)$, and $g$ is the gravitational acceleration $\left(\mathrm{m} \mathrm{s}^{-2}\right)$ (Hwang and Houghtalen 1996). Using Manning's formula, and assuming turbulent flow in the horizontal well pipe (Kim et al. 2008), the friction factor $f$ can be expressed as

$$
f=\frac{124.5 n^{2}}{D^{1 / 3}}
$$

where $n$ is the effective Manning's roughness coefficient. Here, the use of Manning's equation may be questioned for the flow in a pipe that is flowing full. This equation is useful for fully developed turbulent flow regimes where head loss is proportional to the square of the flow velocities. For the laterals used in the study performed by Kim et al. (2008), the Reynolds number ranged from 2000 to30 $\times 10^{3}$. Olson and Wright (1990) showed head loss for this range to be proportional to the power of 1.75 of axial flow velocity. Also, Mohammed and Rushton (2006) used

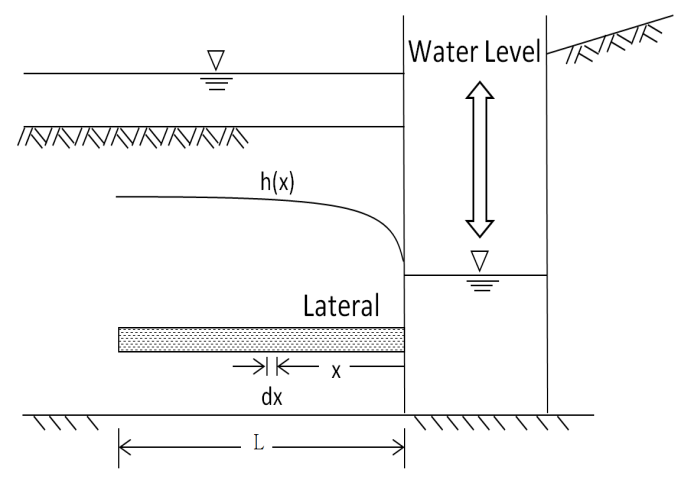

Fig. 1. Coordinate system to analyze the head distribution on a horizontal well used for riverbed filtration. the Hazen-Williams equation in which head loss is proportional to the power of 1.85 of the velocity. From their model study, however, they acknowledged that the use of any alternative expression with the loss proportional to the square of the velocity would not have a significant effect on the overall model results. In their experiment, the Reynolds number was less than 6000. They ascribed the development of more turbulence than described by the Reynolds number to the impact of the inflowing water through the screen walls. They postulated that owing to this effect turbulent flows were likely to occur along the full length of the lateral even at the locations away from the outlet where velocities were low. Based on these findings, Kim et al. (2008) developed a mathematical model employing Manning's equation to describe discharge intensity variations along the laterals. They compared the model predictions with the experimental data and found that the error was minimal. Furthermore, the use of Manning's equation in this study may be acceptable as it makes mathematical manipulation more amenable to develop a closed form equation than expressions containing non-integer powers of axial velocity.

Substitution of Eq. (2) into Eq. (1) yields

$$
\Delta h=\frac{124.5 n^{2}}{D^{4 / 3}} \frac{v^{2}}{2 g} \Delta x
$$

which describes the hydraulic head distribution $h(x)$.

The discharge intensity can be assumed to be uniform across the entire length of the horizontal well if the exit velocity from the well is low (Kim et al. 2008). In this case the axial flow velocity in the well pipe increases linearly from 0 at the end of the well up to the maximum exit velocity. This phenomenon is common to both model and prototype horizontal wells. Therefore, if the exit velocities of both wells are the equal, (e.g., $40 \mathrm{~mm} \mathrm{~s}^{-1}$ ), the axial flow velocity in the horizontal well pipe increases linearly from 0 to $40 \mathrm{~mm} \mathrm{~s}^{-1}$, over a shorter distance in the model well, compared to the prototype wells. Mohamed and Rushton (2006) reported that they obtained only $34 \mathrm{~mm}$ of head difference between both ends of a horizontal well of $150 \mathrm{~m}$ length and $0.15 \mathrm{~m}$ diameter when the exit flow velocity was about $40 \mathrm{~mm} \mathrm{~s}^{-1}$. If the entire length of both model and prototype wells is divided into the same number, say 4 , of segments of equal size, the distance between two neighboring nodes will be larger in the prototype than in the model well. However, the axial flow velocities will be identical at the nodes of the same relative location of both wells. This is schematically shown in Fig. 2, for example, for $2.0 \mathrm{~m}$ and $60 \mathrm{~m}$ laterals.

Given the distribution of the axial flow velocity along the horizontal well and its derivative with respect to distance, $\Delta v / \Delta x$, the discharge intensity in a unit surface 


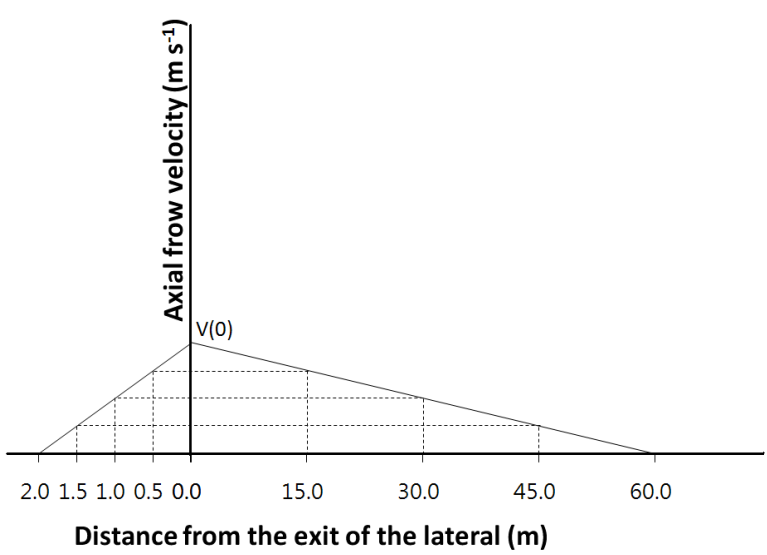

Fig. 2. Equality of axial flow velocities at the same relative locations of the model and prototype laterals when the low exit velocities are identical.

area of the well, $q\left(\mathrm{~m}^{3} \mathrm{~m}^{-2} \mathrm{~s}^{-1}\right)$ can be obtained from the mass balance on water over a short length, $\Delta x$ of the well (Fig. 3) as

$$
q=\frac{D}{4} \frac{\Delta v}{\Delta x}
$$

When the exit velocities are identical and low enough for both model and prototype wells, and when the prototype is, for example, 30 times longer than the model, the $\Delta v / \Delta x$ value can be regarded as being constant throughout the

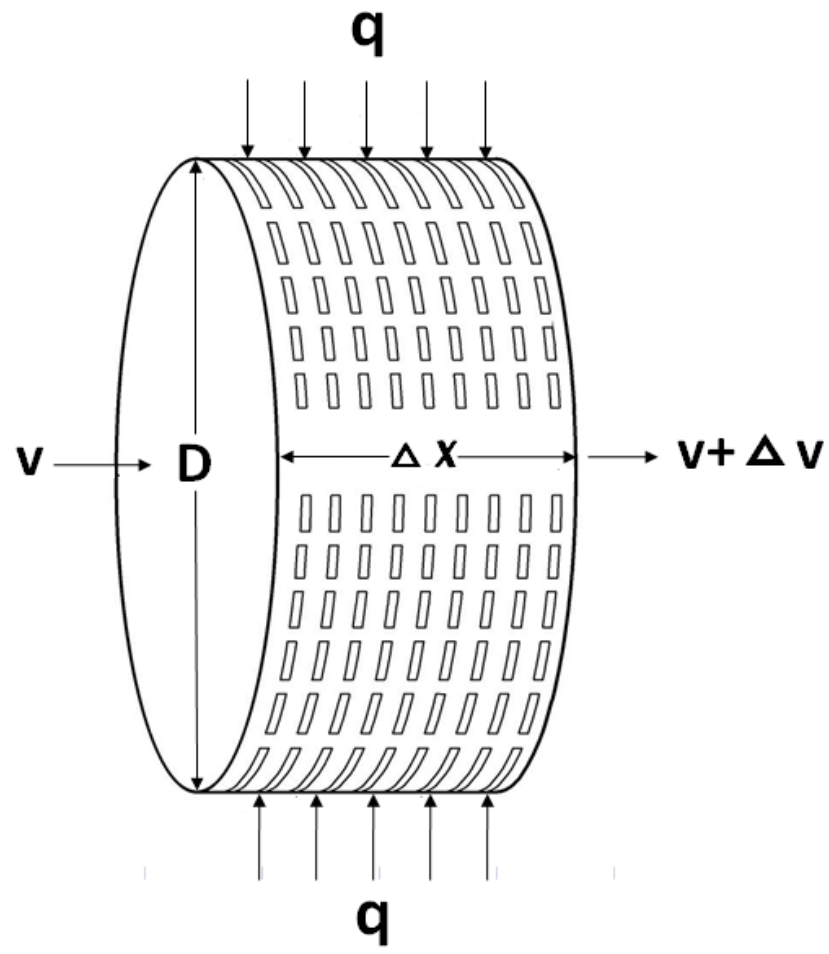

Fig. 3. Water balance over a short length of the horizontal well. entire length of the well and the value for the prototype is $1 / 30$ that of the model well as can be seen in Fig. 2. If the diameter of the prototype well is, for example, 15 times that of the model well, the $q$ value of the prototype well is half the value of the model well. In addition to the lower $q$ value in the prototype well, the well diameter is 15 times larger in the prototype while the axial flow velocities are identical for both wells at the same relative locations. Therefore, the resistance to the axial pipe flow (i.e., the effective roughness coefficient if Manning's formula is employed) in the prototype well is much lower than that in the model since the flow rate of the perpendicularly inflowing filtrate is less in the prototype than in the model while the pipe diameter is larger in the prototype and the axial flow velocities are identical at the same relative locations. In order to generalize this finding, a parameter describing the relative resistance to the axial pipe flow caused by the perpendicularly inflowing filtrate, $q / D$, is introduced. Since the exit velocities of both model and prototype horizontal wells are identical and low, can be expressed as

$$
v(0)=\left(\frac{\Delta v}{\Delta x}\right)_{p} \cdot L_{p}=\left(\frac{\Delta v}{\Delta x}\right)_{m} \cdot L_{m}
$$

or

$$
\frac{\left(\frac{\Delta v}{\Delta x}\right)_{p}}{\left(\frac{\Delta v}{\Delta x}\right)_{m}}=\frac{L_{m}}{L_{p}}
$$

where $L$ denotes the length of the horizontal well (m), and the subscripts "p" and " $m$ " denote the prototype and model wells, respectively. Substitution of Eq. (4) into Eq. (6) gives

$$
\frac{\left(\frac{q}{D}\right)_{p}}{\left(\frac{q}{D}\right)_{m}}=\frac{L_{m}}{L_{p}}
$$

which shows that the relative resistance due to the perpendicularly in-flowing filtrate in the prototype well does not exceed that in the model well unless the latter exceeds the former in length.

Since the head value $h(0)$ at the exit of the well is known, Eq. (3) can be applied node by node from the exit of the well using Euler-Cauchy method (Kreyszig 2006) to determine the head distribution $h(x)$ once all the parameters are known. In addition, because the velocities at the same relative location of both model and prototype wells are identical, the ratio between head losses of both wells at the same relative location can be obtained using Eq. (3) as follows; 


$$
\frac{\Delta h_{p}}{\Delta h_{m}}=\frac{\frac{n_{p}^{2}}{n_{m}^{2}} \frac{\Delta x_{p}}{\Delta x_{m}}}{\frac{D_{p}^{4 / 3}}{D_{m}^{4 / 3}}}
$$

Equation (8) can be rewritten considering Eq. (7) as follows;

$$
\frac{\Delta h_{p}}{\Delta h_{m}}<\frac{\left(\frac{\Delta x_{p}}{\Delta x_{m}}\right)}{\left(\frac{D_{p}}{D_{m}}\right)^{(4 / 3)}}
$$

\section{APPLICATION OF THE THEORY}

A numerical application of Eq. (9) is given as an example. Kim et al. (2008) observed a $65 \mathrm{~mm}$ head difference between both ends of the well when the exit flow velocity was $0.74 \mathrm{~m} \mathrm{sec}^{-1}$ In a model horizontal well of inner diameter $20 \mathrm{~mm}$ and length $1.8 \mathrm{~m}$. Using these values $\mathrm{Eq}$. (9) gives head difference between both ends of a prototype well (50 m long and $0.3 \mathrm{~m}$ in diameter) less than $49 \mathrm{~mm}$ for the same exit flow velocity. This suggests that the hydraulic head over the $50 \mathrm{~m}$-long horizontal well may be regarded as a constant with an error of less than $0.1 \%$. In this case the production rate of the horizontal well amounts to $4520 \mathrm{~m}^{3}$ day $^{-1}$, which may be sufficient for practical purposes of operating horizontal well. This shows that the assumption made by Hantush and Papadopulos (1962) is valid when the exit flow velocity is low enough, and also that the assertion made by Kim et al. (2008), that a highefficiency horizontal well should have its exit velocity

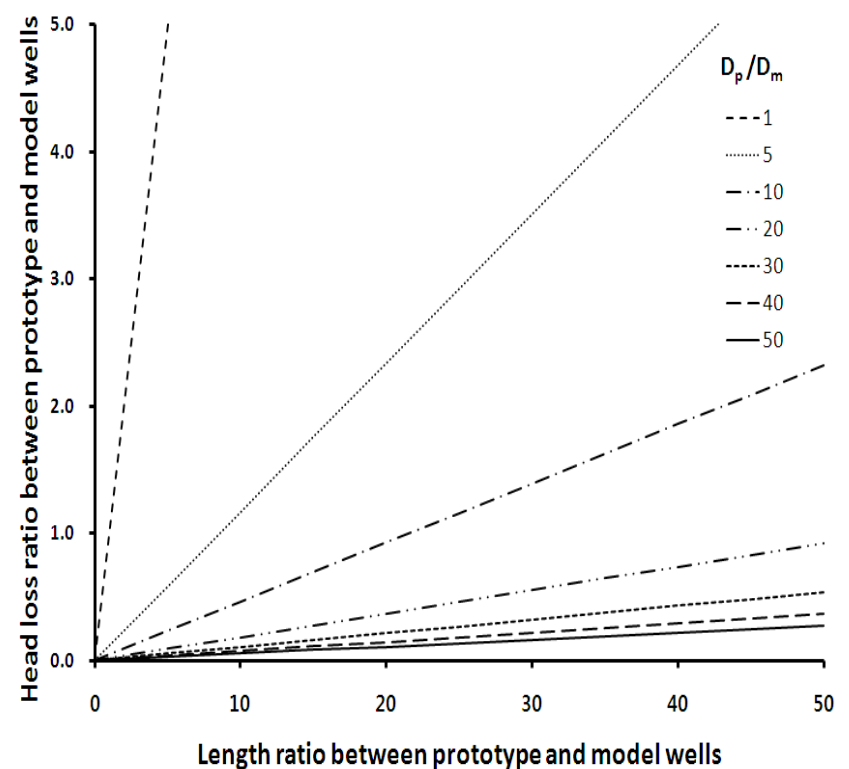

Fig. 4. Head loss ratio between prototype and model horizontal wells according to the scaling-up of the well dimension. maintained below $1 \mathrm{~m} \mathrm{sec}^{-1}$, can be applied to the prototype wells. It can be further determined that, since the head loss reduction by the diameter increase dominates the head loss increase by the lengthening of the well, the head loss in a prototype well (Eq. 9) can effectively be limited by increasing the well diameter (Fig. 4). For example, a 50fold increase in length can be compensated by diameterincrease of only 18.8 -fold. This would result in the same head-loss in the prototype well as in the model. Since the roughness coefficient (i.e., the friction caused by the perpendicularly in-flowing filtrate) of the prototype well is expected to be even smaller than that of the model (Eq. 7), the diameter increase needed may further decrease.

\section{CONCLUSIONS}

The applicability to prototype wells of a suggested maximum design velocity of axial flow of $1 \mathrm{~m} \mathrm{~s}^{-1}$ for an efficient horizontal well, derived using a model experiment (Kim et al. 2008), was investigated. The Darcy-Weisbach equation associated with the Manning's formula was analyzed using the Euler-Cauchy method and the frictional resistance was investigated in the case of both model and prototype laterals. Results showed that the frictional resistance to the axial flow was smaller in the prototype well than in the model well and that the design velocity obtained from the model experiment was also applicable to the prototype wells. However, the results should be applied with caution since the conclusions need to be verified employing a prototype well. It should also be noted that the methodology involves some sources of error since an uniform discharge intensity is assumed over the entire length of the wells. Moreover, the methodology adopted in this study employs a phenomenological rather than hydraulic approach (especially in Fig. 2). In spite of these limitations, the results of this study appear to be useful in practice, especially in the prediction of the production rate by both analytical and numerical methods and in the diameter design of horizontal wells.

\section{ACKNOWLEDGEMENT}

This study was supported by the CAER (Center for Aquatic Ecosystem Restoration) of ECO-STAR project from MOE (Ministry of Environment, Republic of Korea).

\section{REFERENCES}

Chen, C., J. Wan and H. Zhan. 2003. Theoretical and experimental studies of coupled seepage-pipe flow to a horizontal well. Journal of Hydrology 281: 159-171.

Grischek, T., D. Schoenheinz and C. Ray. 2002. Siting and design issues for riverbank filtration schemes. In Riverbank Filtration, Improving Source-Water Quality, eds. C. Ray, G. Melin, and R.B. Linsky, 291302. Dordrecht, The Netherlands: Kluwer Academic Publishers.

Hantush, M.S. and I.S. Papadopulus. 1962. Flow of ground water to collector wells. Journal of Hydraulic Engineering Division 88: 221-245. 
Hunt, H., M. Schubert and C. Ray. 2002a. Conceptual design of riverbank filtration systems. In Riverbank Filtration, Improving Source-Water Quality, eds. C. Ray, G. Melin, and R.B. Linsky, 19-27. Dordrecht, The Netherlands: Kluwer Academic Publishers.

Hunt, H., M. Schubert and C. Ray. 2002b. Operation and maintenance considerations. In Riverbank Filtration, Improving Source-Water Quality, eds. C. Ray, G. Melin, and R.B. Linsky, 61-70. Dordrecht, The Netherlands: Kluwer Academic Publishers.

Hwang, N. H. C. and R. J. Houghtalen. 1996. Fundamentals of Hydraulic Engineering Systems, $3^{\text {rd }}$ edition. New York NY: Prentice Hall.

Jasperse, J. 2009. Planning, design and operations of collector 6, Sonoma County Water Agency. In Riverbank Filtration for Water Security in Desert Countries, eds. C. Ray, and M. Shamrukh, 169-222. Dordrecht, The Netherlands: Springer.

Kim, S-H. 2007. Comparison of riverbank and riverbed filtration in Korea. Journal of Korean Society of Environmental Engineers 29: 1154-1162 (in Korean).

Kim, S-H., H-H.Ahn and C. Ray. 2008. Distribution of discharge intensity along collector well laterals in a model riverbed filtration. Journal of Irrigation and Drainage Engineering Division 134: 493-500.

Kreyszig, E. 2006. Advanced Engineering Mathematics, $9^{\text {th }}$ edition. New York, NY: John Wiley \& Sons.
Mohamed, A. and K. Rushton. 2006. Horizontal wells in shallow aquifers: field experiment and numerical model. Journal of Hydrology 329: 98-109.

Olson, R. M. and S. J. Wright. 1990. Essentials of Engineering Fluid Mechanics, $5^{\text {th }}$ edition. New York, NY: Harper and Row.

Schafer, D.C. 2004. Hydraulic analysis and modeling of riverbank filtration for Louisville water company. In International Workshop on Riverbank/bed Filtration, 99-127. Seoul, South Korea, December 10.

Stowe, M. S. 2004. Application of horizontal collector well technology for riverbank filtration. In International Workshop on Riverbank/bed Filtration, 35-97. Seoul, South Korea, December 10.

Tarshish, M. 1992. Combined mathematical model of flow in an aquifer-horizontal well system. Ground Water 30: $931-935$.

Wang, J. 2002. Riverbank Filtration Case Study at Louisville, Kentucky. In Riverbank Filtration, Improving Source-Water Quality, Eds. C. Ray, G. Melin, and R.B. Linsky, 117-145. Dordrecht, The Netherlands: Kluwer Academic Publishers.

Zhan, H. and E. Park. 2003. Horizontal well hydraulics in leaky aquifers. Journal of Hydrology 281: 129-146. 